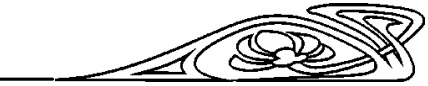

УДК 525.35:551.583:551.468:551.31.32:38.61.15

\title{
О ВЛИЯНИИ РОТАЦИОННОГО РЕЖИМА ЗЕМЛИ НА ПРИРОДНЫЕ ПРОЦЕССЫ
}

\author{
Л.А. Назаркин \\ Научно-исследовательский институт естественных наук \\ Саратовского государственного университета, \\ кафедра геологии и геохимии горючих ископаемых \\ E-mail:Kam@rambler.ru
}

Установлена зависимость приземной температуры воздуха в фанерозойское время от ротационного режима Земли. Эпохи похолоданий коррелируются с уменьшением скорости земного вращения. Макроколебания ротационного режима, порождаемые космогенными и эндогенными факторами, так же как и микроколебания, обусловленные флюктуациями солнечной активности и эндогенными процессами, контролируют напряжения и деформации в земной коре, динамику и особенности циркуляции водных и воздушных масс и как следствие температурный режим широтных поясов. Рассмотрено влияние ротационного режима Земли на пластовую миграцию флюидов и его возможное влияние на нефтегазоносность северного борта Прикаспийской впадины.

On Influence of the Earth's Rotational Regime upon Natural Processes

\section{L.A. Nazarkin}

Dependence of the near-surface air temperature on the Earth's rotational regime is revealed in the Phanerozoic. Epochs of cooling correlate with reduced rates of the Earth's rotation. Macrovariations in rotational regime caused by cosmogenic and endogenic factors, and microvariations, as well as by fluctuations in solar activity and endogenic processes, control the stresses and deformations within the Earth's crust, dynamics and peculiarites of water and air mass circulation, and consequently, the temperature regimes of the latitudinal belts. The influence of the rotational regime on the stratum migration of fluids and its possible impact on the oil and gas contents in the northern border of the Peri-Caspian Depression is considered.

Вращающаяся Земля в сочетании с флюктуациями солнечного теплового облучения являет собой тепловую машину, регламентирующую прогрев водных и воздушных масс и их широтную и меридиональную циркуляцию [1-6].

В этой связи трудно переоценить результаты исследований J.W. Wels [7] и S.K. Runcom [8], а также материалы исследований других палеонтологов, приведенные Z.Kukal [9], свидетельствующие о флюктуационном уменьшении в фанерозойское время суточных ритмов в годичном цикле. По суточным ритмам роста кораллов, моллюсков и строматолитов установлено, что в докембрии число суточных ритмов в годичном цикле составляло 880 , в кембрии - 424, в $O_{2}-412$, в $S-410$, в $D_{1}-410$, в $D_{2}-405.5$, в $D_{3}-398$, в $C_{3}-380-390$, в $T-371.6$, в $K-375$.

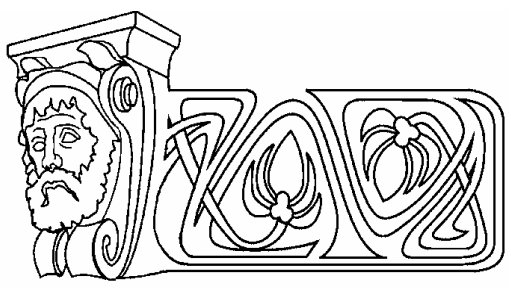

Фундаментальное объяснение природы долгопериодных изменений ротационного режима Земли дается астрофизиками. Об этом свидетельствуют материалы, приведенные A.C. Мониным [5], убеждающие в том, что важнейшую роль в изменении ротационного режима Земли в фанерозое играла эволюция системы Земля-Луна. В соответствии с законами небесной механики скорость вращения Земли находится в обратной зависимости от расстояния между Луной и Землей. А.С. Монин ссылается на расчеты Т. Макдональда (1964), согласно которым при минимальном удалении Луны от Земли (2.72 земных радиуса), имевшем место 1.79 млрд лет назад, скорость вращения Земли была в 5 раз выше современной. С того момента, вследствие начавшегося удаления Луны, вращение Земли замедляется. Этому также способствует аналогичное воздействие Солнца, по силе вдвое меньшее, нежели лунное, вследствие большего удаления от Земли $[5,10]$. Согласно расчетам А.С. Монина, в настоящее время из-за уменьшения скорости вращения Земли продолжительность суток увеличивается на 1.7 мс за столетие.

Многие геологи и геофизики [11-15] полагают, что замедление скорости вращения Земли в фанерозойское время - следствие ее пульсационного расширения. О росте и дыхании Земли в свое время писал и Леонардо да Винчи [16].

Предполагается [15], что 1.6 млрд лет назад радиус Земли был на $45 \%$ меньше современного. В дальнейшем (в интервале $1.6-1.0$ млрд. лет) началось пульсационное увеличение объема Земли. Е.Е.Милановский [11] полагает, что спрединговое расширение океанического дна порождало трансгрессии (вследствие уменьшения глубин океанов и роста срединно-океанических хребтов) и усиление вулканической активности. 
Сопоставление хода изменения среднегодовой температуры в фанерозойское время с приведенными выше палеонтологическими данными об изменении скорости вращения Земли свидетельствует об уменьшении температур воздуха при спадах скорости ее вращения (рис.1). Так, уменьшение скорости вращения Земли в конце ордовика и карбона, установленное по палеонтологическим данным, оказывается синхронным понижениям приземной температуры (эпохи формирования покровных оледенений). Цикличность изменения климатических условий в фанерозойское время в связи с изменением скорости вращения Земли установлено А.В.Орловой [17]. Нет сомнения, что новая информация о флюктуациях скорости вращения Земли также найдет подтверждение в изменениях приземной температуры в соответствии с проявляющейся зависимостью.

В этой связи нельзя согласиться с А.С.Мониным [5] в том, что периоды ускорения вращения Земли, «когда наклон (земной оси. Л.Н.) был меньше, чем сейчас... были более благоприятными для развития оледенений в полярных районах и прилегающих к ним континентах» [5, с.49]. Ускорение земного вращения возникло на завершающем этапе формирования ледников, когда из-за связывания океанской воды в высокоширотных ледниковых массивах Земля «худела», что порождало увеличение скорости ее вращения и как следствие усиление выноса тепла водными и воздушными массами в высокие широты. Последнее вызывало таяние льда, повышение уровня океана. Увеличение земного радиуса в низких широтах в связи с повышением уровня океана (и сопряженной с ним трансгрессией) замедляло скорость вращения Земли и приводило к понижению приземной температуры воздуха. Опираясь на эмпирические данные, Н.А. Ясаманов [18-19] пришел к выводу, что «развитие трансгрессий, начиная с силурийского периода, всегда сопровождалось не повышением, а некоторым понижением температуры» [19, с.32].

Трансгрессии порождают мелководье. Д.Г. Тарлинг [20] пришел к выводу, что «...наличие мелководных континентальных морей, расчленяющих континентальный блок и обеспечивающих в высокоширотной его части влагой, создают наиболее благоприятные условия для возникновения покровного оледенения» [20, с.38]. Обратная зависимость накопления снега в Антарктиде от скорости вращения Земли проявляется в результатах исследования Н.С. Сидоренкова [21].

Таким образом, возникновение глобальных оледенений могло происходить при замедлении скорости вращения Земли, вызванного космическими (или эндогенными) факторами, а их деградация возникала вследствие увеличения скорости ее вращения при уменьшении земного радиуса в низких широтах из-за связывания больших объемов водных масс в высокоширотных ледниках.

Ряд исследователей [22-26] рассматривают периодические изменения скорости вращения Земли как фактор, вызывающий образование трещиноватости земной коры, инициирующий тектоническую (и вулканическую) активность. Происходящая при этом активизация эндогенных процессов в условиях нарушения герметизации земных недр благоприятствует выделению $\mathrm{CO}_{2}$ в атмосферу и как следствие повышению приземной температуры воздуха за счет «парникового эффекта» (удвоение концентрации $\mathrm{CO}_{2}$ в современной атмосфере вызвало бы увеличение температуры на $2.5^{\circ}$ ) [19, 25-28 и др.].

Предполагается [23, 29], что максимальное воздействие на деформации земной коры оказывают резкие спады скорости вращения Земли. Согласно расчетам Л.С. Лейбензона [29], для достижения предела упругости литосферы достаточно удлинения суток на 11 мин, которое происходит в течение 3540 млн лет и соответствует тектоническому циклу второго порядка. По этой причине в литосфере возникают напряжения, разрядка которых проявляется в деформациях земной коры и сопряженных с ними рудообразованиях. Разломы земной коры активизировали вулканическую деятельность и как следствие последней - выброс в атмосферу вулканической пыли, ослабляющей проявление «парникового эффекта» за счет выделения $\mathrm{CO}_{2}$. М.И.Будыко [30] полагает, что запыленность атмосферы могла способствовать возникновению ледниковых эпох.

«Парниковый эффект» оказывал существенное влияние на приземную температуру, которая проявляется в заметной корреляции «всплесков» концентрации $\mathrm{CO}_{2}$ с положительными температурными аномалиями (см. рис.1). 


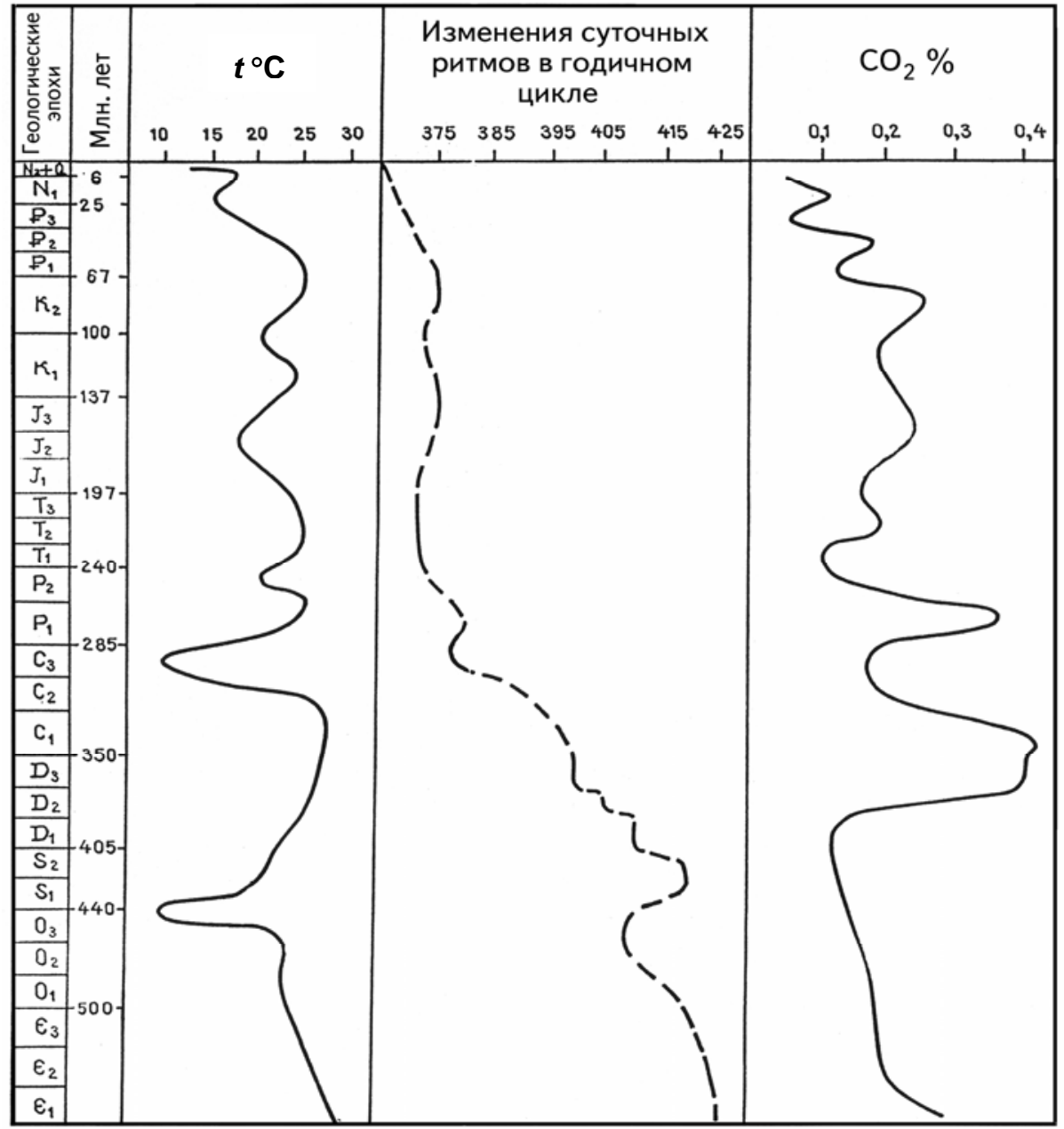

Рис.1. Изменение среднегодовой приземной температуры и концентрации $\mathrm{CO}_{2}$ в фанерозойское время в связи с изменением скорости вращения Земли $[9,19,27]$

На фоне макроколебаний скорости вращения Земли, обусловленных ритмикой космогенных и эндогенных процессов, установлены короткопериодные флюктуации ротационного режима с изменением длины суток всего на десятые-сотые доли миллисекунд $[18,22,31,32]$.

По мнению Н.Н. Парийского [22], микроколебания скорости земного вращения следствие эндогенной эволюции Земли. Вместе с тем в публикациях И.П. Дружинина и Н.В. Хомьяновой [32], В.М. Киселева [2], Л.И. Мирошниченко [4], Ю.Д.Калинина [1] и других авторов приводятся доказательства прямой зависимости незначительных (а периодами - и значительных) колебаний скорости вращения Земли от изменения солнечной активности. Последнее наглядно подтверждается при сопоставлении графиков скоро- сти вращения Земли и изменения солнечной активности за последние 250 лет (рис.2).

Исследуя природу вариаций скорости вращения Земли, В.М.Киселев [2] и Ю.Л.Калинин [1] пришли к выводу о зависимости ротационного ее режима как от колебательно-вращательных движений в системе ядрооболочка, так и от воздействия на оболочку флюктуаций солнечной активности и сопряженной с ней, меняющейся силы воздействия на магнитосферу солнечного ветра. Увеличение скорости (и плотности) солнечного вет$\mathrm{pa}$, сопряженное с увеличением солнечной активности, уменьшает радиус магнитосферы Земли и как следствие вызывает увеличение скорости ее вращения.

При статистической обработке данных об изменении солнечной активности и ротационного режима Земли за последние два 


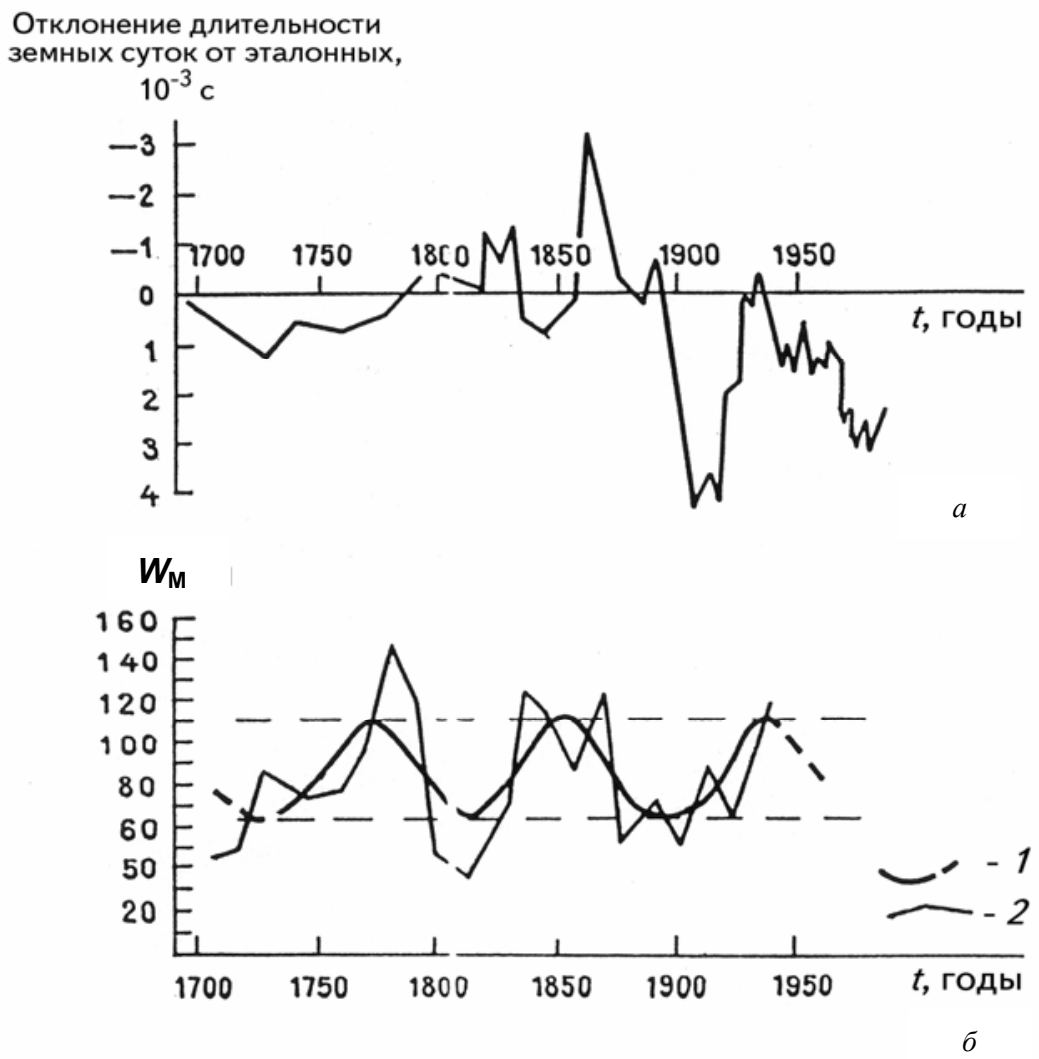

Рис. 2. Изменения скорости вращения Земли и векового цикла солнечной активности $W_{\mathrm{M}}[12,18]: a$ - отклонение длительности земных суток от эталона; $\sigma$ - изменение солнечной активности; 1 - несглаженные, 2 - сглаженные данные; 3 - точки наблюдения

столетия В.М. Киселев установил, что коэффициент корреляции между изменениями скорости вращения Земли и сглаженными 11-летними средними значениями чисел Вольфа равен 0.89. Зависимость скорости вращения Земли от изменения скорости солнечного ветра во временном интервале $1962-$ 1974 гг. характеризуется значением $r=0.88$. И в первом и во втором примерах увеличение чисел Вольфа и скорости солнечного ветра вызывает ускорение вращения Земли. Отсутствие однозначной зависимости - свидетельство «глушения» солнечного воздействия на ротационный режим Земли эндогенными процессами. Последнее можно увидеть и на рис. 2 .

Находясь под контролем ротационного режима Земли, динамика водной и воздушной циркуляции четко реагирует на существенные изменения солнечной активности и сопряженного с ней земного вращения. И.В. Максимов [33, 34], используя метеолетопись последних столетий, наглядно иллюс- трирует прямую зависимость среднего уровня океана у атлантических берегов Северной Америки, ослабления ледовитости северной части Атлантического океана и толщины годовых колец секвой в Калифорнии от солнечной активности. Иллюстрацией прямой зависимости от скорости вращения Земли переноса водных масс в высокие широты может быть график корреляции меридиональной циркуляции вод Северной Атлантики и колебания полюса вращения Земли (последние зависят от скорости вращения Земли $[34$, с.348]), составленный Н.П. Смирновым [35]. Из-за уменьшения скорости вращения Земли вынос теплых вод Гольфстримом через Фареро-Шетландский пролив по замерам в июне 1947-1952 гг. сокращался в 5 раз (рис.3).

С ускорением вращения Земли сопряжено усиление пассатов и порождаемых ими апвеллингов. Одним из подтверждений реальности этой зависимости может быть обогащение органическим веществом осадков 


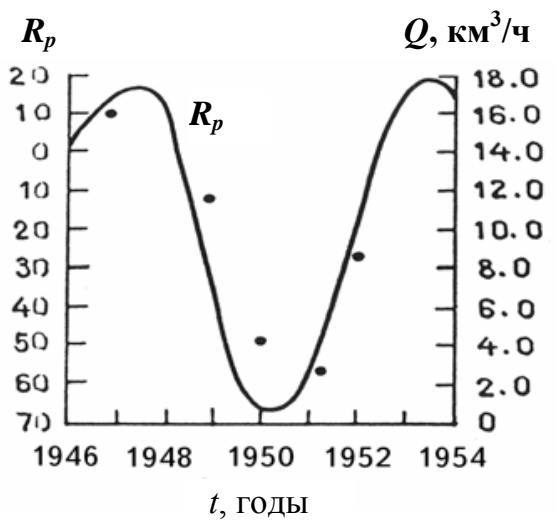

Рис.3. Корреляция статистического индекса меридиональной циркуляции вод Северной Атлантики через Фареро-Шетландский пролив в июле и нутационных колебаний полюса вращения Земли [35]: • - точки наблюдения

апвеллинговых зон, синхронных ледниковым эпохам [36-40]. В данном случае усиление апвеллинга и сопряженного с ним повышения биологической продуктивности фотического слоя воды происходит из-за увеличения скорости земного вращения вследствие уменьшения земного диаметра в низких широтах по причине связывания воды в высокоширотных ледниках.

Резкие кратковременные спады скорости вращения Земли, вызывающие замедления воздушной и водной циркуляции в низких широтах, иногда порождают драматические события. Так, спад солнечной активности 1982-1983 гг. [38] стал причиной уменьшения скорости вращения Земли [41-42]. Последнее существенно ослабило силу пассатов и как следствие вызвало затухание апвеллингов, повышение температуры поверхностного слоя воды в море на $6^{\circ} \mathrm{C}[2,39-41]$. В данном случае повышение температуры воды - следствие затухания апвеллингов и уменьшения выноса прогретых вод в высокие широты из-за ослабления приэкваториальной циркуляции водных масс.

По мнению У.Е. Картера и Д.С. Робертсона [42], спад скорости вращения Земли в 1982-1983 гг. - главная причина возникновения катастрофического по своим последствиям Эль-Ниньо ${ }^{1}$, когда из-за затухания апвеллингов близ перуанского и эквадорского по-

1 Эль-Ниньо (по-испански - младенец) - спорадически (в среднем через 6-8 лет) возникающие аномальные потепления вод у побережья Эквадора и Перу, губительно сказывающиеся на продуктивности морского биоса [39]. бережий погибали кормовые угодья промысловых рыб, креветок, ластоногих и птиц. Оазис жизни в пределах апвеллинговых зон превратился в пустыню, усеянную трупами морских обитателей. Ураганы, возникающие в зонах проявления Эль-Ниньо, оборвали около тысячи жизней. Убытки составили более 8 млрд долл.

Ураганами и катастрофическими ливнями вновь заявил о себе Эль-Ниньо летом 1997 года ${ }^{2}$. Весь спектр разрушительных событий, связанных с этим явлением, обычно реализует себя в осенне-зимнее (максимум) и весеннее время. При этом экстремальные погодные условия следует ожидать не только в тропических и субтропических зонах, где они проявляют себя максимально, но и в средних и высоких широтах.

В свое время исследователей Южного океана озадачил феномен аномального дрейфа айсбергов в низкие широты в 1888-1897 годах [34]. Как представляется И.В. Максимову, аномальный вынос айсбергов в низкие широты - следствие аномального увеличения скорости вращения Земли. Он в графической форме [34] отразил положение айсбергов в Южном океане в 1889-1897 и 1954-1958 годах. В первый временной интервал, характеризующийся предшествующей аномально высокой скоростью вращения Земли (см. рис.2), айсберги (на фоне центробежного сгона воды в низкие широты [3]) дрейфовали до 40-й параллели. В отдельных направлениях они оказались на 1700 км ближе к экватору по сравнению с положением фронта фиксации айсбергов в 1954-1958 гг., когда проявился резкий спад действия ротационных сил.

Судя по всему, длительное ускоренное вращение Земли в 1860-1897 гг. (см. рис.2) одна из главных причин упоминаемого И.В.Максимовым аномального по продолжительности «потепления Арктики» [34, с.244] в данный временной интервал. Произошло это вследствие увеличения выноса теплых водных и воздушных масс в высокие широты.

Исследуя природу различного гипсометрического уровня водонефтяного контакта на северных и южных крыльях складок грозненских и дагестанских нефтяных скоп-

\footnotetext{
19 июля.
} 
лений, Б.Н. Викторов [43] обосновывает понижение нефтяных контактов на северных крыльях усилением подтока нефти с пластовыми водами за счет центробежных сил вращения Земли. По его расчетам, на широте $45^{\circ}$, где максимально проявляются центробежные силы, последние способны перемещать флюиды по восстанию пласта под углом подъема, не превышающим $24^{\circ}$.

Проявление ротационных сил в пластовых условиях локальных структур позволяет рассматривать их как реальный фактор региональных миграционных процессов при условии учета палеоширотного положения и меридиональной ориентации палеобассейнов в период формирования скоплений углеводородов. В этой связи влияние ротационных сил следует иметь в виду при прогнозировании локализации углеводородных скоплений в мегабассейнах с пологим углом наклона напластований.

В качестве примера возможного влияния ротационных сил на региональную нефтегазоносность может служить северный борт Прикаспийской впадины, где многолетние поисковые работы пока не увенчались открытием крупных скоплений нефти и газа. Одной из причин поисковых неудач может быть центробежный сгон флюидов в южном направлении, где они улавливались (накапливались) в благоприятных структурнотектонических условиях.

На земной поверхности широтная составляющая ротационных сил (силы Кориолиса), в десятки раз меньшая, по сравнению с центробежными, законом Бэра проявляет себя отступающими к западу (вследствие подмыва) крутым правым берегом меридионально текущих рек северного полушария и левым - южного.

Изложенное позволяет прийти к выводу, что и в геологическом прошлом пульсационные изменения скорости вращения Земли оказывали большое влияние на ход климатических процессов. Усиление земного вращения порождало усиление меридиональных перемещений водных и воздушных масс, усиление апвеллингов, повышение среднегодовой температуры и понижение меридиональных температурных градиентов. По мнению J.A. Kitchell и D.L. Klark [44], усиление меридиональной циркуляции водных масс в конце мелового периода и в начале палеогена (когда имело место увеличение скорости вращения Земли - рис.1) - главная причина высокоширотного апвеллинга в Ледовитом океане. Спады скорости вращения Земли ослабляли меридиональную циркуляцию водных и воздушных масс и как следствие понижали среднегодовую приземную температуру, увеличивали межширотные температурные контрасты, ослабляли апвеллинг.

Генерализованно спад скорости вращения Земли в фанерозое, особенно в посткарбоновое и постмеловое время, коррелируется как с флюктуационным понижением среднегодовой приземной температуры воздуха (см. рис.1), так и с понижением широтного положения внешней границы субтропиков (рис.4).

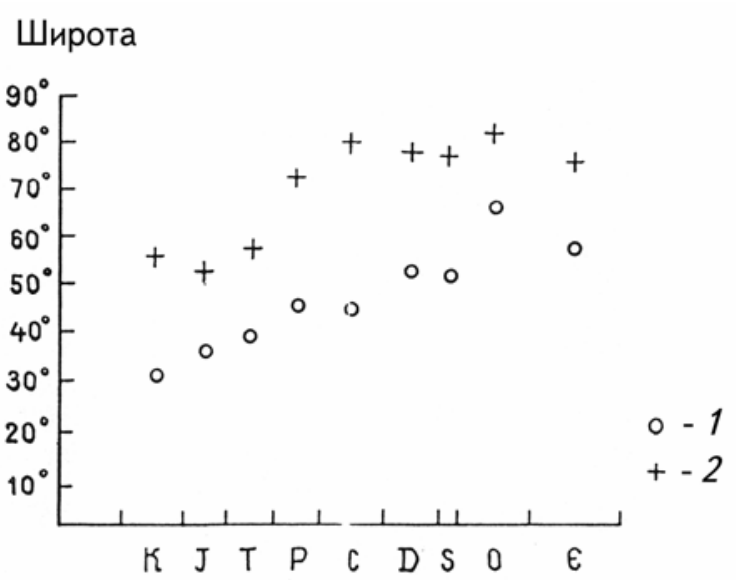

Рис. 4. Изменение широтного положения внешней границы субтропической зоны в фанерозойское время [45]: 1 - максимальное удаление от экватора, 2 - среднее положение

Таким образом, ротационный режим Земли сказывается как на напряжениях (и деформациях) земной коры и как следствие на углекислом дыхании недр, определяющем степень проявления «парникового эффекта» повышения наземной температуры, так и на динамике циркуляции водных и воздушных масс, регламентирующей меридиональный перенос тепла, от которого зависят межширотные температурные контрасты.

Влияя на апвеллинги, ротационный режим Земли контролирует биологическую продуктивность тропической зоны океанов. Спад скорости вращения порождает ЭльНиньо с характерным для этого явления резким понижением биологической продуктив- 
ности, тогда как ускорение вращения влечет за собой всплеск продуктивности гидробионтов. Одним из подтверждений последнего являются обогащенные органическим веществом прослои в колонках океанских осадков, синхронные ледниковым эпохам, когда вследствие падения уровня океана в низких широтах (из-за связывания океанской воды в высокоширотных ледниках) Земля ускоряла вращение, вызывающее усиление выноса в фотический слой биогенных элементов.

Зависимость циркуляции водных и воздушных масс от микро- и макроколебаний ротационного режима Земли, вызываемых флюктуациями солнечной активности и эндогенными процессами, свидетельствует о несомненной актуальности учета данного фактора при долгосрочных гидрометеорологических прогнозах.

Актуально и проявление влияния ротационного режима Земли на формирование скоплений углеводородов и на динамику пластовых вод. Исследование зависимости миграции пластовых флюидов в период генерации материнскими толщами углеводородов от проявления центробежных сил может открыть путь к познанию природы особенностей формирования как локальных скоплений нефти и газа, так и закономерностей расположения нефтегазовых скоплений в пределах платформенных палеоседиментационных бассейнов, отличающихся малыми углами наклона напластований.

\section{Библиографический список}

1. Калинин Ю.Д. Вековые геомагнитные вариации. Новосибирск, 1984. $160 \mathrm{c}$.

2. Киселев В.М. Неравномерность суточного вращения Земли. Новосибирск, 1980. 160 с.

3. Максимов И.В., Смирнов Н.П. Изменения скорости вращения Земли и средний уровень Мирового океана // Океанология. 1964. T.IV, вып.1. С.9-18.

4. Мирошниченко Л.И. Солнечная активность и Земля. М., 1981. $144 \mathrm{c}$.

5. Монин А.С. Вращение Земли и климат. Л., 1972. 112 с.

6. Усманов Р.Ф. О влиянии вращения Земли на общую циркуляцию атмосферы // Тр. Центрального ин-та погоды. 1961. Вып.104. С.3-10.

7. Wells J.W. Coral growth and geochronometry // Nature. 1963. V.197. P.948-950.

8. Runcom S.K. Coral and the history of the earth's rotation // Sea Front. 1967. V.13, №1. P.91-99.
9. Kufcal Z. The rate of geological processes // Earth-Science Reviews. 1990. V.28, №1. P.1-284.

10. Манк У., Макдональд Г. Вращение Земли. М., 1964. 384 с.

11. Милановский E.E. Развитие и современное состояние проблем расширения и пульсаций Земли // Проблемы расширения и пульсаций Земли. М., 1984. С.8-24.

12. Нейман В.Б. Расширяющаяся Земля. М., 1962.80 c.

13. Crawford A.R. The myth at a vast oceanic Tethys, the India-Asia problem and Earth expansion // J. Petrol. and Geol. 1979. V.2, №1. P.3-9.

14. Ricard N.J., Belbin L. A new continental assembly for Pangea // Tectonophysics. 1980. V.63. P.1-12.

15. Schmidt P.W., Embleton B.J.J. A geotectonic paradox: Has the Earth expanded? // J. Geophys. 1981. V.49, №1. P.20-25.

16. Леонардо да Винчи. Избранные произведения. М.; Л., 1935. T.1. $366 \mathrm{c}$.

17. Орлова А.В. Изменение климата Земли как показатель неравномерности скорости ее вращения // Проблемы планетарной геологии. Л., 1963. С.52-121.

18. Куликов К.А. Вращение Земли. М., 1985. 159 с.

19. Ясаманов Н.А. Причины климатических колебаний в фанерозое // Изв. АН СССР. Сер. географ. 1991. №1. С.20-35.

20. Тарлинг Д.Г. Геологические и геофизические аспекты ледниковых эпох. Изменения климата. Л., 1980. С.16-44.

21. Сидоренков Н.С. Неправильности вращения Земли как возможные показатели глобального водообмена // Метеорология и гидрология. 1980. №1. С.52-59.

22. Парийский Н.Н. О нерегулярных изменениях скорости вращения Земли и возможной связи их с деформациями Земли и изменениями силы тяжести // Проблемы расширения и пульсации Земли. М., 1984. С.84-93.

23. Стовас М.В. Некоторые вопросы тектогенеза // Проблемы планетарной геологии. М., 1963. С.222-274.

24. Шульы С.С. Тектоника земной коры (на основе анализа новейших движений). Л., 1979. 272 с.

25. Брукс К. Климаты прошлого. М., 1952. 357 с.

26. Тяпкин К.Ф., Кивелюк Т.Т. Изучение разломных структур геолого-геофизическими методами. М., 1982. 239 с.

27. Будыко М.И., Ронов А.Б. Эволюция химического состава атмосферы в фанерозое // Геохимия. 1979. №5. C.643-653.

28. Бубнов В.А. Циркуляция вод экваториальной зоны Мирового океана. Л., 1990. 280 c.

29. Лейбензон Л.С. Собрание трудов: В 4 т. Гидроаэродинамика, геофизика. М., 1955. Т.4. 399 с.

30. Будыко М.И. О происхождении ледниковых эпох // Метеорология и гидрология. 1968. №11. С.3-12.

31. Дружинин И.П., Хомьянова Н.В. Солнечная активность и переломы хода природных процессов на Земле. М., 1969. $224 \mathrm{c}$.

32. Morrison L.V. Rotation of the Earth from 1663-1972 // Nature. 1973. V.241, №5391. P.519-521.

33. Максимов И.В. Вековые колебания ледовитости северной части Атлантического океана // Тр. Ин-та океанологии. 1954. T.VIII. C.41-91. 
34. Максимов И.В. Геофизические силы и воды океана // Л., $1973.448 \mathrm{c}$.

35. Смирнов Н.П. Долгопериодные ритмические явления в деятельности Гольфстрима. // Изв. Всесоюз. геогр. о-ва. 1965. №5. С.427-437.

36. Максимов И.В., Смирнов Н.П. Изучение причин многолетних изменений в деятельности Гольфстрима // Океанология. 1965. Т.5, вып.3. С.210-221.

37. Muller P.J., Suess F. Productivity, sedimentation rate, and sedimentary organic matter in oceans. 1. Organic carbon preservation // Deep-Sea Research. 1979. V.26, №12A. P.1347-1362.

38. Мигулин В.В. Больше внимания солнечно-земной физике // Вестн. АН СССР. 1991. №11. С.55-62.

39. Федоров К.Н. Этот капризный младенец - Эль-Ниньо! // Природа. 1984. №8. С.65-74.
40. Barber R.T., Clavez F.P. Biological concequences of El Nino // Science. 1983. V.222, №4629. P.1203-1210.

41. Barrentos C.S. El Nino-Southern oscillation episode of 1982-83 // Mariner's Weather Log. 1984. V.28, №2. P.81-84.

42. Картер У.Е., Робертсон Д.С. Исследования Земли с помощью интерферометрии со сверхдлинной базой // В мире науки. 1987. №1. С.16-25.

43. Викторов Б.Н. Влияние центробежной силы вращения Земли на формирование нефтяных и газовых залежей // Нефтяное хозяйство. 1954. №2. С.42-46.

44. Kitchell J.A., Clark D.L. Late cretaceous-paleogene paleogeography and paleocirculation: evidence of north polar upwelling // Palaeogeography, Palaeoclimatology, Palaeoecology. 1982. V.40, №1-3. P.135-136.

45. Опдайк Н.В. Палеоклиматология и дрейф континентов // Дрейф континентов. Горизонтальные движения земной коры. М., 1966. С.159-182. 